\title{
Author Correction: The molecular Lego movie
}

Arash Nikoubashman and Friederike Schmid

Correction to: Nature Chemistry https://doi.org/10.1038/s41557-019-0243-8, published online 22 March 2019.

In the version of this News \& Views originally published, in the sentence starting "Now, such a self-assembly process has been monitored...", the term 'transition electron microscopy' should have read 'transmission electron microscopy'; this has now been corrected.

Published online: 24 April 2019

https://doi.org/10.1038/s41557-019-0268-z

\section{Publisher Correction: Toxic thallium}

Anders Lennartson

Correction to: Nature Chemistry https://doi.org/10.1038/nchem.2286, published online 23 June 2015.

In the version of this In Your Element originally published, in the final sentence of the first paragraph, 'element 64' should have read 'element 81'.

Published online: 11 April 2019

https://doi.org/10.1038/s41557-019-0267-0

\section{Publisher Correction: Roaming-mediated ultrafast isomerization of geminal tri-bromides in the gas and liquid phases}

Andrey S. Mereshchenko, Evgeniia V. Butaeva, Veniamin A. Borin, Anna Eyzips and Alexander N. Tarnovsky

Correction to: Nature Chemistry https://doi.org/10.1038/nchem.2278, published online 15 June 2015.

In the version of this Article originally published, in Fig. 5, the chemical formula $\mathrm{Br} \bullet \mathrm{CC}_{6} \mathrm{H}_{11}$ should have read $\mathrm{Br} \bullet \mathrm{CH}_{3} \mathrm{C}_{6} \mathrm{H}_{11}$. 